\title{
OPEN Comprehensive assessment of harmful heavy metals in contaminated soil in order to score pollution level
}

\begin{abstract}
Haodong Zhao ${ }^{1,2}$, Yan Wu ${ }^{1,2}$, Xiping Lan ${ }^{3}$, Yuhong Yang ${ }^{4}$, Xiaonan Wu ${ }^{1,2}$ \& Liyu Du ${ }^{1,2 \bowtie}$
Soil-related problems have grown up to be a major threat to human society. Scientific evaluation is helpful to understand the status of soil pollution and provide reference to further work. In this situation, Liaoning Province, a typical industrial and agricultural province in Northeast China, was selected as a case study region. It reviewed 200 studies published between 2010 and 2020 and recorded related data of soil heavy metal. It used model method and index method to evaluate the agricultural region. The comprehensive assessment score of Liaoning pollution level was 0.8998 . Dalian was 0.9536 , ranking first among the 14 cities. Huludao and Jinzhou were 0.7594 respectively, ranked the last. Heavy metal accumulation in different cities stemmed from different sources, including weathering of parent materials, industrial wastes, sewage irrigation, and mining activities. In general, the pollution level of heavy metal in Liaoning was at low risk level, but it still needs to pay attention to the health risk of heavy metal and the input of heavy metal into the soil, especially cadmium (Cd). This study provides a comprehensive assessment of soil heavy metal pollution in Liaoning, while identifying policy recommendations for pollution mitigation and environmental management.
\end{abstract}

Heavy metals are common pollutants in the soil environment, namely arsenic (As), cadmium (Cd), chromium $(\mathrm{Cr})$, mercury $(\mathrm{Hg})$, lead $(\mathrm{Pb})$, copper $(\mathrm{Cu})$, zinc $(\mathrm{Zn})$, nickel $(\mathrm{Ni})$. This type of contamination is biologically toxic, widely distributed, and persists long-term in soil environment ${ }^{1}$. With the rapid development of economy and society, a variety of heavy metals contaminated soil threatens the environment and public health ${ }^{2}$. In China, soil in the agricultural regions has been partly contaminated by heavy metal, which lead to the decreasing availability of farmland ${ }^{3}$. The over standard rate of soil pollution is $16.1 \%$, among which the $\mathrm{Cd}, \mathrm{As}, \mathrm{Hg}, \mathrm{Pb}, \mathrm{Cr}$ over standard rates of heavy metals are as high as $7.00 \%, 2.70 \%, 1.60 \%, 1.50 \%, 1.10 \%$, respectively ${ }^{4}$. In 2009 , the global emission of heavy metal Cd reached 743.77 tons $^{5}$. Over the past 50 years, around 30,000 tons of $\mathrm{Cr}$ and 800,000 tons of $\mathrm{Pb}$ have been released into the environment around the world ${ }^{6}$. Most of these heavy metals have already been accumulated in the soil. However, chronic exposure to heavy metal has harmful consequences for human beings like lung cancer, bone fractures ${ }^{7,8}$. Under the circumstance, remediation techniques of contaminated soil and pollution assessment have been widely concerned both domestically and globally.

A lot of studies have been conducted on remediation techniques for heavy metal polluted soil, including insitu remediation techniques (surface capping, encapsulation, electrokinetic extraction, soil flushing, chemical immobilization, phytoremediation, bioremediation) and ex-situ remediation techniques (landfilling, soil washing, solidification, vitrification $)^{9,10}$. These remediation techniques focus on reducing the maximum or bioavailable concentration of heavy metal in the soil ${ }^{11,12}$. Although these methods have high performance, most of them are expensive, harmful to the environment and time-consuming ${ }^{13,14}$. These traditional methods to remediate polluted soil have many limitations and a certain degree of threat. Therefore, it is essential to deploy scientific pollution assessment and advanced remediation technologies that can effectively and safely remediate heavy metal polluted soil ${ }^{15}$.

\footnotetext{
${ }^{1}$ College of Land and Environment, Shenyang Agricultural University, Shenyang, Liaoning, China. ${ }^{2}$ Northeast Key Laboratory of Conservation and Improvement of Cultivated Land (Shenyang), Ministry of Agriculture, P.R. China National Engineering Laboratory for Efficient Utilization of Soil and Fertilizer, Shenyang, Liaoning, China. ${ }^{3}$ Rural Energy and Environmental Protection Department, Liaoning Agricultural Development Center, Shenyang, Liaoning, China. ${ }^{4}$ College of Bioscience and Biotechnology, Shenyang Agricultural University, Shenyang, Liaoning, China. ${ }^{\varpi}$ email: duliyu2006@syau.edu.cn
} 


\begin{tabular}{|l|l|l|l|l|l|}
\hline City & Number of points & $\mathbf{p H}<\mathbf{5 . 5 0}$ & $\mathbf{5 . 5 0} \leq \mathbf{p H}<\mathbf{6 . 5 0}$ & $\mathbf{6 . 5 0} \leq \mathbf{p H}<\mathbf{7 . 5 0}$ & $\mathbf{p H} \geq \mathbf{7 . 5 0}$ \\
\hline Shenyang & 99 & 45 & 22 & 22 & 10 \\
\hline Dalian & 30 & 8 & 10 & 10 & 2 \\
\hline Anshan & 71 & 20 & 17 & 25 & 9 \\
\hline Fushun & 29 & 16 & 10 & 1 & 2 \\
\hline Benxi & 22 & 13 & 5 & 3 & 1 \\
\hline Dandong & 36 & 19 & 11 & 4 & 2 \\
\hline Jinzhou & 84 & 34 & 20 & 15 & 15 \\
\hline Yingkou & 35 & 6 & 13 & 13 & 3 \\
\hline Fuxin & 48 & 17 & 11 & 9 & 11 \\
\hline Liaoyang & 30 & 13 & 13 & 4 & 0 \\
\hline Panjin & 22 & 1 & 3 & 6 & 12 \\
\hline Tieling & 63 & 20 & 18 & 17 & 8 \\
\hline Chaoyang & 59 & 7 & 13 & 15 & 24 \\
\hline Huludao & 82 & 46 & 23 & 12 & 1 \\
\hline Total & 710 & 265 & 189 & 156 & 100 \\
\hline
\end{tabular}

Table 1. Number of samples and $\mathrm{pH}$ value of 14 cities in Liaoning province.

Heavy metal pollution assessment of farmland soil is great significance to control and mitigate the increasingly severe soil heavy metal pollution. It is the foundation and premise to reduce the risk of heavy metal pollution. The commonly used methods of assessing heavy metal pollution of soil locally and internationally can be roughly divided into the index and model methods. The index methods include single pollution, pollution load, and cumulative indexes, etc. The model methods include the enrichment factor method and potential ecological hazard index method, etc. ${ }^{16}$. At present, there is no unified standard for the evaluation of soil environmental quality at home and abroad ${ }^{17}$. On the one hand, the existing evaluation methods have their own advantages and disadvantages ${ }^{18,19}$. As the pollution range contained in the function is too narrow, grey clustering will appear unreasonable phenomenon ${ }^{20}$. Nemero index overemphasizes the influence of the highest score index ${ }^{21}$. On the other hand, the studies mainly focus on the key areas, such as sewage irrigation area, mine area ${ }^{22}$. And most studies only focus on one specific heavy metal, such as $\mathrm{Hg}$, As and $\mathrm{Cd}^{23}$. Furthermore, various stakeholders such as regulatory authorities, landowners, and academia may have different interests and views on the effectiveness of remediation ${ }^{24}$. These limitations seriously affect our overall knowledge on heavy metal pollution level. Therefore, more scientific, more comprehensive, and more reliable macro-evaluation method is a top priority need.

For fill this gap, this study determined the concentrations of heavy metal in 710 soil samples from 14 cities in Liaoning agricultural sites. These soil samples are a collection of data from other published works. This study defined the weight coefficients of 8 heavy metals and 4 soil quality indexes. It used geostatistics and fuzzy mathematics to analyse harmful heavy metals in soil to further understand the impact of human activities on the quality of farmland soil. On the basis, the heavy metal pollution level and associated risk were evaluated. The objectives were as follows: (1) To analyze the heavy metal accumulation in different cities. (2) To evaluate potential ecological risk of heavy metal in soil on the city level. (3) To determine the health risk caused by heavy metal in three exposure pathways. (4) To analyze the relationship of 8 heavy metals through principal component analysis (PCA) and correlation analysis (CA). (5) To establish a score approach based on soil quality indexes to comprehensively assessment contaminated soil pollution level. It will enhance our knowledge of the comprehensive soil heavy metal pollution status across Liaoning and provide valuable information for soil management, soil remediation and soil contamination control.

\section{Materials and methods}

Data collection and processing. Liaoning is the core area of the northeast old industrial base ${ }^{25}$. This study reviewed a series of studies on soil heavy metals in agricultural regions of Liaoning published between 2010 and 2020. The main literature databases including Web of Science, China National Knowledge Infrastructure (CNKI). The sampling processing methods used in the selected literature have been widely accepted by the scientific community. The studies used should meet the following regulations: (1) The soil samples should be collected from the soil at depth within $20 \mathrm{~cm}$. 3-5 soil samples were taken at each sampling site, and then mixed thoroughly to give a composite sample ${ }^{26}$. (2) Soil samples treatment and chemical analysis process of the selected studies should comply with the requirements listed in the HJ/T166-2004 ${ }^{27}$. This study collected 8 heavy metal concentrations of 710 sampling sites in agricultural regions from 200 studies. And the sample numbers in different cities are presented in Table 1.

Single factor assessment. Single factor index is the simplest soil environmental quality index ${ }^{28,29}$. Heavy metal concentrations were compared to standards $(\mathrm{GB} 15618-2018)^{30}$. In the calculation process, it is important to exclude outliers from the data matrix according to statistical methods. See supplementary materials for boxplot method.

The specific calculation formula is as follows: 


$$
m=C_{i} / C_{n}
$$

where $m$ is a single factor index, $C_{i}$ is the measured value of ground $i$ term factor, $C_{n}$ is the standard value of the i-th factor.

Geological accumulation index assessment. The geological accumulation index $\left(\mathrm{I}_{\text {geo }}\right)$ was proposed by Müller ${ }^{31}$ and has been widely used in heavy metal studies ${ }^{32}$. The enrichment of heavy metals in the soil can be determined by comparing the current values with the background values. The $\mathrm{I}_{\text {geo }}$ of the tested soil was calculated using the following equation:

$$
I_{\text {geo }}=\log _{2}\left(C n / 1.5 B_{n}\right)
$$

where $C_{n}$ is the measured concentration of every heavy metal found in farmland soil (mg/kg), and $B_{n}$ is the geological chemical background value (Table S1) of the heavy metals found in soil ( $\mathrm{mg} / \mathrm{kg}$ ). See supplementary materials for other details (Table S2).

Ecological risk index assessment. The potential ecological risk index (ER) was used to determinate the potential ecological risk of heavy metal accumulation in soil ${ }^{33}$. Soil heavy metal potential ecological risk assessment is carried out soil heavy metal properties and environmental behavior. It can also take into account the synergistic effects of various elements, pollution level, and environmental associations with heavy metal. The integrated potential ecological risk index (RI) combines the value of ER of each heavy metal. The specific calculation formula is as follows:

$$
\begin{gathered}
C F=C n(\text { sample }) / C n(\text { Crust }) \\
E R=\operatorname{Tr} \times C F \\
R I=\sum E r
\end{gathered}
$$

where $\operatorname{Tr}$ is the toxicity coefficient and CF is the pollution factor. See supplementary materials for other details (Tables S3 and S4).

Health risk assessment. Human health risk assessment is the process of assessing the nature and possibility of adverse health effects in humans who may be exposed to chemicals in polluted environmental media. Potential non-carcinogenic health risk and potential carcinogenic health risk (PCR) can be estimated by target hazard quotients $(\mathrm{HQ})$ and the hazard index $(\mathrm{HI})^{34-36}$. $\mathrm{HI}>1$ implies potential non-carcinogenic risk. If the total potential carcinogenic health risk (TCR) is greater than $1 \times 10^{-4}$, it indicates a high carcinogenic risk to human body. If the TCR is less than $1 \times 10^{-6}$, it means the potential carcinogenic health caused by heavy metal exposure can be negligible. There are three exposure routes (ingestion, dermal absorption, and breathing inhalation) to evaluate the health risk of heavy metal in soil. See supplementary materials for additional details.

Comprehensive assessment. The comprehensive assessment was divided according to three steps: index determination, weight analysis, and quantitative analysis. The sub-objectives of comprehensive assessment were split into the following categories: single factor assessment (SF), geo-accumulation assessment (GEO), potential ecological risk assessment (PER) and human health risk assessment (HHR). The four indexes were combined in a more comprehensive index to analyze the heavy metal pollution level of farmland soil. Analytic hierarchy process (AHP) and Delphi method were used to determine the membership degree of the evaluation indexes. In the comprehensive assessment, the core idea is to quantify evaluation index and transform it into a quantitative value $^{37}$. The comprehensive assessment score value ranged from 0.00 to 1.00 . The higher the score, the lower the pollution level was. The scoring basis was obtained from current national, industry standard, or related theoretical studies.

There are 20 scientists from soil science, heavy metal pollution, environmental impact assessment, and other fields. They were invited for the questionnaire survey which aimed to determine the importance of matrices among the four methods. The importance of assessment methods was compared using Saaty's scale of 1-9 (Table S5) and a comparative judgment matrix was constructed (Table S6). Finally, surveys were summarized to calculate the matrices and the final weight through a consistency test. The steps of the summary method were in supplement material. The weight coefficient specific calculation formulas are presented in Eq. (6) and Eq. (7). The comprehensive assessment calculation formulas are shown in Eq. (8) and Eq. (9). This assessment method can digitize the pollution level of the heavy metal and directly assess pollution status by using a score.

$$
\begin{gathered}
\sum_{i=1}^{n} W i=1 \\
W i=T i / \sum_{i=1}^{n} T i
\end{gathered}
$$




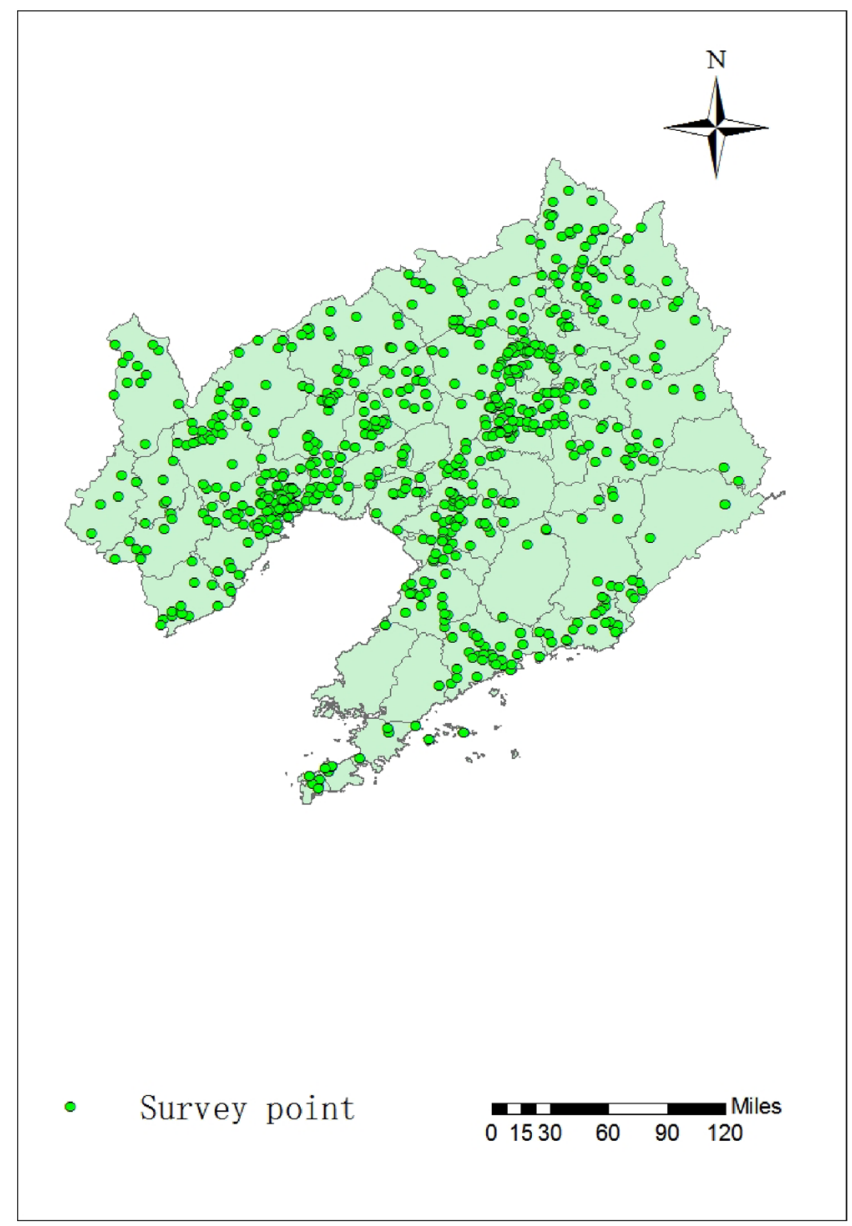

Figure 1. Distribution of sampling sites in Liaoning province, China. The map was created in ArcMap 10.2: https://www.esri.Com (Esri, California, USA).

$$
\begin{aligned}
& T=\sum_{i=1}^{n} M i \times W i \\
& M i=\sum_{i}^{m} S i \times W s
\end{aligned}
$$

$\mathrm{T}_{\mathrm{i}}$ represents the toxic coefficients of one certain heavy metal. T represents the total score of the comprehensive assessment result. $\mathrm{M}_{\mathrm{i}}$ represents the score of one certain evaluation method. $\mathrm{S}_{\mathrm{i}}$ represents the score of one certain heavy metal. $\mathrm{W}_{\mathrm{i}}$ represents the weight of one certain assessment method, and $\mathrm{W}_{\mathrm{s}}$ represents the weight of one certain heavy metal.

Ethical approval and consent to participate. Written informed consent for publication of this paper was obtained from the Shenyang Agricultural University of Land and Environment and all authors.

Consent to publication. Written informed consent was obtained from the authors for publication of this report and any accompanying images. A copy of the written consent is available for review by the Editor-in-Chief of this journal.

\section{Results and discussion}

Distribution of examined sites. 710 survey points in agricultural regions were distributed in 14 cities of Liaoning province (Fig. 1). In general, the survey points were densely distributed in the Shenyang, Jinzhou, Huludao, Anshan and Tieling. The number of agricultural sites survey points was 399 in these cities. But obviously sparse in other cities. Benxi and Panjin had the least number of agricultural sites survey points at 22. On the one hand, the distribution pattern was consistent with the overall distribution of agricultural regions throughout Liaoning, and these points in the area with large planting regions. On the other hand, the obtained 
data of this study had a good representation, because it contained current common different cultivated land types in Liaoning. Due to the large proportion of food, fruit and vegetables in the diet, the main types of agriculture in the survey sites were food crops, fruit plantations, and vegetable plantations. In particular, the sampling sites of major crops such as corn and rice were more densely distributed. In addition, soil $\mathrm{pH}$ values of 710 survey sites are shown in Table 1, among which the soil $\mathrm{pH}$ values are less than 6.50 , accounting for $63.95 \%$ of the total number of points. The activity of heavy metals in the soil under acidic conditions will increase compared with neutral and alkaline conditions ${ }^{38}$. Therefore, it should pay more attention to prevent soil from acidification.

Overview of heavy metals concentration in soil. The mean concentrations and percentile values of heavy metal are shown in Fig. 2. The mean concentrations of Cd $(0.56 \pm 0.78 \mathrm{mg} / \mathrm{kg}, 0.76 \pm 0.86 \mathrm{mg} / \mathrm{kg}$, $0.50 \pm 0.16 \mathrm{mg} / \mathrm{kg}$ ) were higher than the standard (GB15618-2018) in Jinzhou, Huludao and Benxi $(0.30 \mathrm{mg} /$ $\mathrm{kg}$ ). In most cities, 75th and 95th percentile values of $\mathrm{As}, \mathrm{Cd}, \mathrm{Cr}, \mathrm{Pb}, \mathrm{Cu}$ and $\mathrm{Ni}$ exceeded the environmental quality standard. On the whole, the situation of $\mathrm{Cd}$ contaminated was not optimistic. The Cd 50th percentile values of Jinzhou and Huludao were already higher than the threshold value. The pollution situation in these two areas was relatively serious. It was similar to the research results of other scholars ${ }^{39}$. Except Panjin and Chaoyang, the Cd 75th and 95th percentile values of other cities exceeded the standard in varying degrees. Liaoning is an important area of the northeast industrial base, rich in mineral resources. The Cd concentration in the atmosphere around the industrial area is generally high, which enters the soil through rainfall or sedimentation, resulting in the higher $\mathrm{Cd}$ concentration in industrial soil ${ }^{40}$. The 95 th percentile values of $\mathrm{As}$ and $\mathrm{Pb}$ in $\mathrm{Dan}-$ dong were far higher than the standard value. It was found that these points in Dandong are located around the Qingchengzi lead-zinc tailings, which further confirms that the mining industry contributes a lot to the heavy metal in the soil ${ }^{41}$. The 95 th percentile values of other heavy metal content only slightly exceeded the standard in a few cities, but these were all within the controllable range. In general, the overall quality of farmland soil was still at low risk level except for several key areas.

Geological accumulation assessment. Though the 14 cities were different in populations and sizes, the $\mathrm{I}_{\text {geo }}$ of 8 heavy metals in soil showed similar trends (Fig. 3). The $\mathrm{I}_{\text {geo }}$ values of $\mathrm{As}, \mathrm{Cr}, \mathrm{Pb}, \mathrm{Cu}, \mathrm{Zn}$ and Ni in most cities were at unpolluted or unpolluted to moderately polluted level (class 1 , class 2 ). The order of mean $\mathrm{I}_{\text {geo }}$ values was $\mathrm{Cd}(1.53)>\mathrm{Hg}(1.09)>\mathrm{As}(0.69)>\mathrm{Zn}(0.66)>\mathrm{Ni}(0.58)>\mathrm{Cu}(0.33)>\mathrm{Cr}(0.06)>\mathrm{Pb}(-0.01)$. The $\mathrm{I}_{\text {geo }}$ values for $\mathrm{Cd}$ showed the strongest variation, varying from unpolluted to heavily polluted level (class 5 ). The $\mathrm{I}_{\text {geo }}$ values for $\mathrm{Hg}$ in some cities (Benxi, Dandong, Chaoyang and Jinzhou) were at moderately to heavily polluted level. The $\mathrm{I}_{\text {geo }}$ values for $\mathrm{Cd}$ in Jinzhou and Huludao were at the heavily polluted level, and $\mathrm{I}_{\text {geo }}$ values of Cd in Yuhong (Shenyang) district was at the moderately to heavily polluted level. In general, the accumulation of heavy metals in soil showed an upward trend, which was mostly related to human activities.

Potential ecological risk assessment. The order of potential ecological harm degree of heavy metal was as follows: $\mathrm{Cd}>\mathrm{Hg}>\mathrm{As}>\mathrm{Cu}>\mathrm{Ni}>\mathrm{Pb}>\mathrm{Cr}>\mathrm{Zn}$. The ER values for $\mathrm{As}, \mathrm{Cr}, \mathrm{Hg}, \mathrm{Pb}, \mathrm{Cu}, \mathrm{Zn}$, and Ni in all cities were in the low risk (class 1). The statistics of ER and RI for heavy metal are shown in Table S8. The ER values for Cd in 13 cities (except Jinzhou) were at low risk (Class 1), and the higher ER values for Cd were found in seven regions (Yuhong, Yixian, Taihe, Linghai, Lianshan, Longgang and Nanpiao). The RI values in 14 cities in Liaoning were lower than 150, indicating that these cities are facing lower potentially l ecological risk of heavy metal accumulation. In general, heavy metal in the topsoil of most cities in Liaoning had low or medium potential ecological risks.

Human health risk assessment. The HI and TCR values of adult citizens in Liaoning are shown in Fig. 4. The distributions of HQ for heavy metals in soil in the study region were ranked as follows: $\mathrm{As}>\mathrm{Pb}>\mathrm{Cu}>\mathrm{C}$ $\mathrm{d}>\mathrm{Zn}>\mathrm{Ni}>\mathrm{Cr}>\mathrm{Hg}$. The $\mathrm{HI}<1$ indicates that the study area may have no non-carcinogenic risk for adults. However, the TCR values of heavy metals in some urban soil should be paid more attention. Because the other six heavy metals do not have carcinogenic slope factors, As and Cd were assessed for carcinogenic risk merely. The order of adult HQ values of three exposure routes was as follows: ingestion > dermal absorption > breathing inhalation. For adult, the oral ingestion of soil was the primary dangerous route of exposure. The TCR values of adult in Yingkou, Benxi, Huludao, Jinzhou and Anshan were higher than the threshold, while the TCR values of other cities were lower than the threshold. Anshan, Benxi, Jinzhou, Huludao and Yingkou were famous as the mineral mining around the country. Large quantities of heavy metals released in the environment through solid wastes, waste water, and waste gas which was discharged from the activities related to mineral mining and metal smelting ${ }^{42,43}$. This ultimately caused relatively high health risks from heavy metal exposure in these areas. As showed in Fig. 1, many survey points were distributed on the cultivated land around the mining area. The cultivated land around the mining area had unacceptable health risks.

Comprehensive assessment of heavy metals pollution level. In terms of the assessment method weight coefficient distribution, there was an obvious bias because the assessment with larger weight was concentrated in SF (0.55) and Geo (0.25). The weight ratio of the two factors was nearly $80 \%$. The weight coefficient of PER and HHR was 0.10 respectively. This trend was consistent with the current practices of soil metal remediation, whose focus was metal content reduction in soil. In terms of heavy metal weight coefficient distribution, Cd (0.31) and $\mathrm{Hg}(0.41)$ accounted for more in the 8 heavy metals. The other six heavy metals (As, $\mathrm{Cr}, \mathrm{Pb}, \mathrm{Cu}, \mathrm{Zn}$, $\mathrm{Ni}$ ) only accounted for $0.10,0.02,0.05,0.05,0.01,0.05$, respectively. The grading and assigning of the four evaluation methods are shown in Table 2. Comprehensive evaluation results of heavy metal pollution level are shown in Fig. 5. Total score of Liaoning pollution level was 0.8998 . The score arrangement order of the evaluation method 

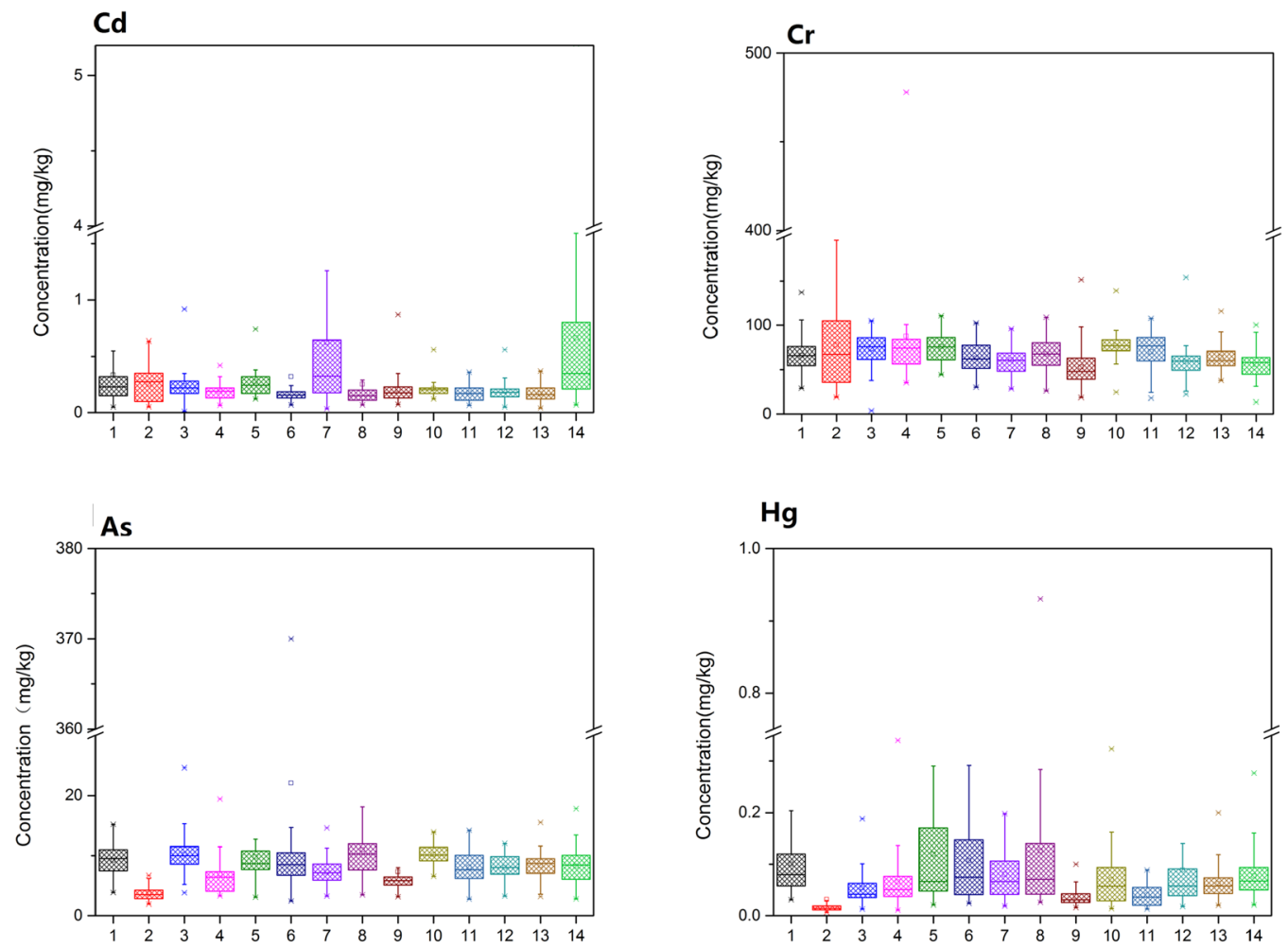

$\mathrm{Pb}$
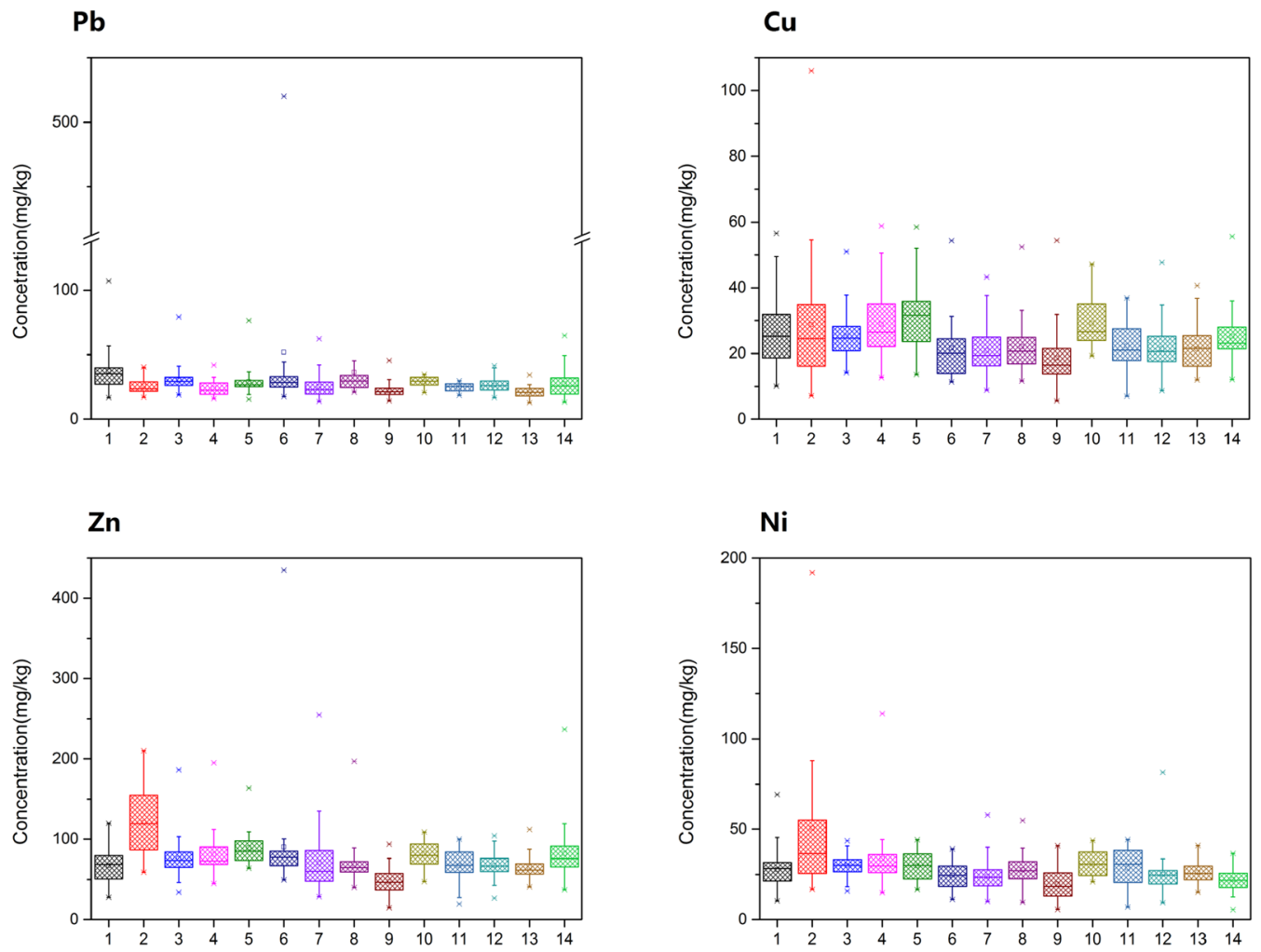

Figure 2. Concentrations of heavy metals in agricultural regions. The Box-and-Whisker plots show the minimum value(lower whisker), 25th quartile, median, 75th quartile, and maximum value (upper whisker) and outlier (.). (Code: 1: Shenyang, 2: Dalian, 3: Anshan, 4: Fushun, 5: Benxi, 6: Dandong, 7: Jinzhou, 8: Yingkou, 9: Fuxin, 10: Liaoyang, 11: Panjin, 12: Tieling, 13: Chaoyang, 14: Huludao). 

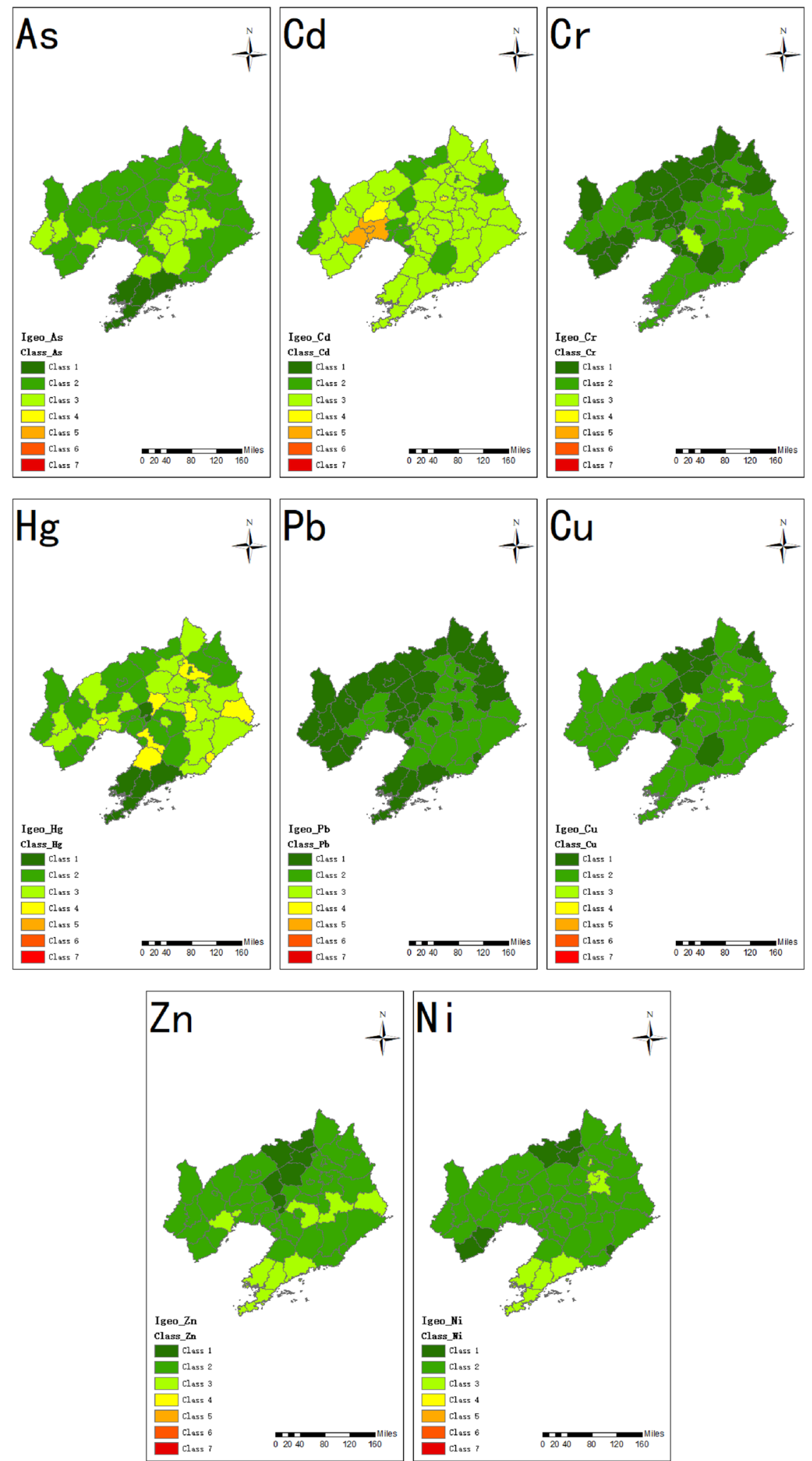

Figure 3. The geo-accumulation index of heavy metals in soil in Liaoning. The map was created in ArcMap 10.2: https:// www. esri. Com (Esri, California, USA). (Class 1: unpolluted; Class 2: unpolluted to moderately polluted; Class 3: moderately polluted; Class 4: moderately to heavily polluted; Class 5: heavily polluted; Class 6: heavily to extremely polluted; Class 7: extremely polluted). 


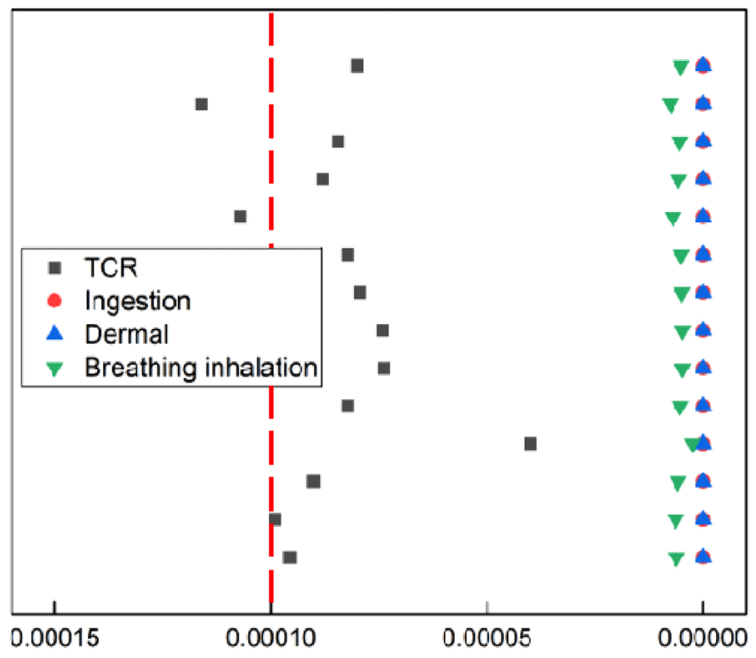

Polential carcinogenic health risk

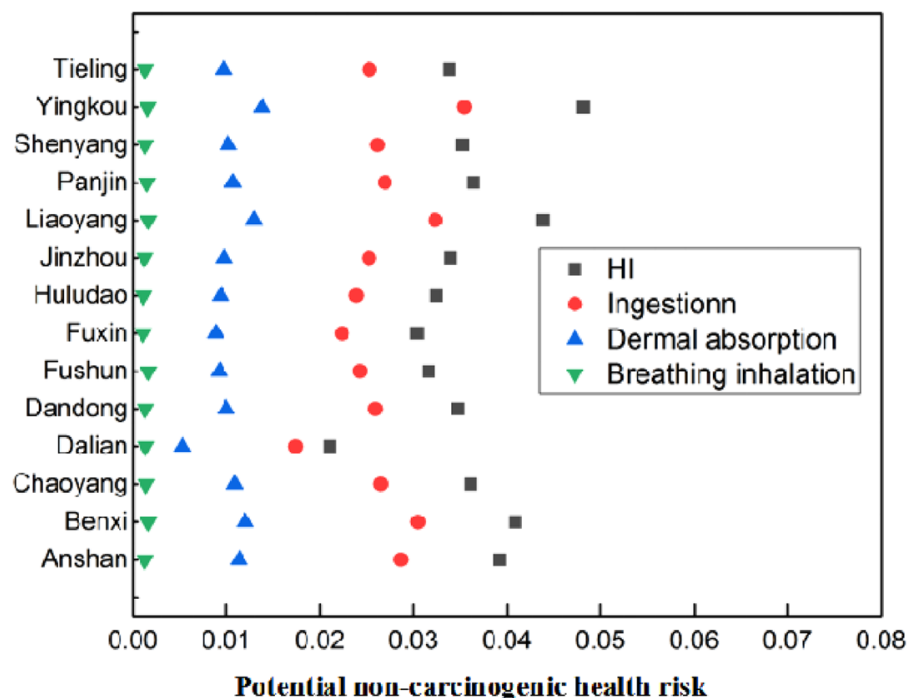

Potential non-carcinogenic health risk

Figure 4. HI and TCR for adults caused by heavy metal in Liaoning province.

\begin{tabular}{|c|c|c|c|}
\hline Assessment method & Score & Scoring basis & Reference \\
\hline \multirow{3}{*}{ Single factor assessment } & 1.00 & $\mathrm{Pi}<1$ & \multirow{3}{*}{$\begin{array}{l}\text { Xu et al. }{ }^{28} \\
\text { Yuan and Lei }{ }^{52}\end{array}$} \\
\hline & 0.70 & $\mathrm{Pi}=1$ & \\
\hline & 0.10 & $\mathrm{Pi}>1$ & \\
\hline \multirow{7}{*}{ Geo-accumulation assessment } & 1.00 & Igeo $\leq 0$ & \multirow{7}{*}{$\begin{array}{l}\text { Müller }^{31} \\
\text { Ji et al. }\end{array}$} \\
\hline & 0.86 & $0<$ Igeo $\leq 1$ & \\
\hline & 0.71 & $1<$ Igeo $\leq 2$ & \\
\hline & 0.57 & $2<$ Igeo $\leq 3$ & \\
\hline & 0.43 & $3<$ Igeo $\leq 4$ & \\
\hline & 0.29 & $4<$ Igeo $\leq 5$ & \\
\hline & 0.14 & Igeo $>5$ & \\
\hline \multirow{4}{*}{ Potential ecological risk assessment } & 1.00 & $\mathrm{RI}<150$ & \multirow{4}{*}{$\begin{array}{l}\text { Hakanson }^{33} \\
\text { Hu et al. (2020) }\end{array}$} \\
\hline & 0.70 & $150 \leq \mathrm{RI}<300$ & \\
\hline & 0.40 & $300 \leq \mathrm{RI}<600$ & \\
\hline & 0.10 & $\mathrm{RI} \geq 320$ & \\
\hline \multirow{3}{*}{ Human health risk assessment } & 1.00 & $\mathrm{HI}<1$ and $\mathrm{TCR}<0.000001$ & \multirow{3}{*}{$\begin{array}{l}\text { Wang et al. }{ }^{51} \\
\text { Zhao et al. }{ }^{37}\end{array}$} \\
\hline & 0.70 & $\mathrm{HI}=1$ or $0.0001<\mathrm{TCR} \leq 0.000001$ & \\
\hline & 0.10 & $\mathrm{HI}>1$ or $\mathrm{TCR}>0.0001$ & \\
\hline
\end{tabular}

Table 2. Comprehensive assessment scoring criteria. The calculation formula of single factor pollution index is as follows: $\mathrm{Pi}=\mathrm{Ci} / \mathrm{S}, \mathrm{Pi}$ is the single factor index of pollutants. $\mathrm{Ci}$ is the measured concentration $(\mathrm{mg} / \mathrm{kg}) . \mathrm{S}$ is the heavy metal risk screening value (mg/kg) (GB 15618-2018). See supplementary materials for other details.

was similar to that weight coefficient order, $\mathrm{M}_{\mathrm{SF}}(0.5346)>\mathrm{M}_{\mathrm{GEO}}(0.2067)>\mathrm{M}_{\mathrm{PER}}(0.1000)>\mathrm{M}_{\mathrm{HHR}}(0.0585)$. Generally, the pollution level of heavy metal in Liaoning was at low risk level, but it still needs to pay attention to the health risk of heavy metal and the input of heavy metal into the soil. The comprehensive assessment score of Dalian was 0.9536 , ranking first among the 14 cities, indicating that the environmental quality is good. However, Huludao and Jinzhou comprehensive assessment score was 0.7594 respectively, ranked the last. It can clearly compare the pollution situation among different regions by comprehensive score.

Source analysis of heavy metals pollution. Heavy metals correlation analysis (CA) can judge the similarity of their sources. Generally, heavy metals with high correlation coefficient may have similar sources. Heavy metals with low correlation coefficient or negative correlation may have different sources. From the correlation analysis results (Fig. 6), it can be seen that there is a positive correlation between the eight heavy metals. It indicated that the pollution sources of the 8 heavy metals were similar. The correlation coefficients of As and $\mathrm{Pb}(\mathrm{r}=0.845, P<0.01), \mathrm{Cr}$ and $\mathrm{Ni}(\mathrm{r}=0.713, P<0.01)$ were greater than 0.70 , which indicated that the pollution sources of $\mathrm{As}$ and $\mathrm{Pb}, \mathrm{Cr}$ and $\mathrm{Ni}$ may be the same. The correlation coefficients of heavy metals were less than 0.30 , like As and $\mathrm{Ni}(\mathrm{r}=0.100, P<0.01), \mathrm{Hg}$ and $\mathrm{Cu}(\mathrm{r}=0.174, P<0.01)$, indicating that these elements were not 


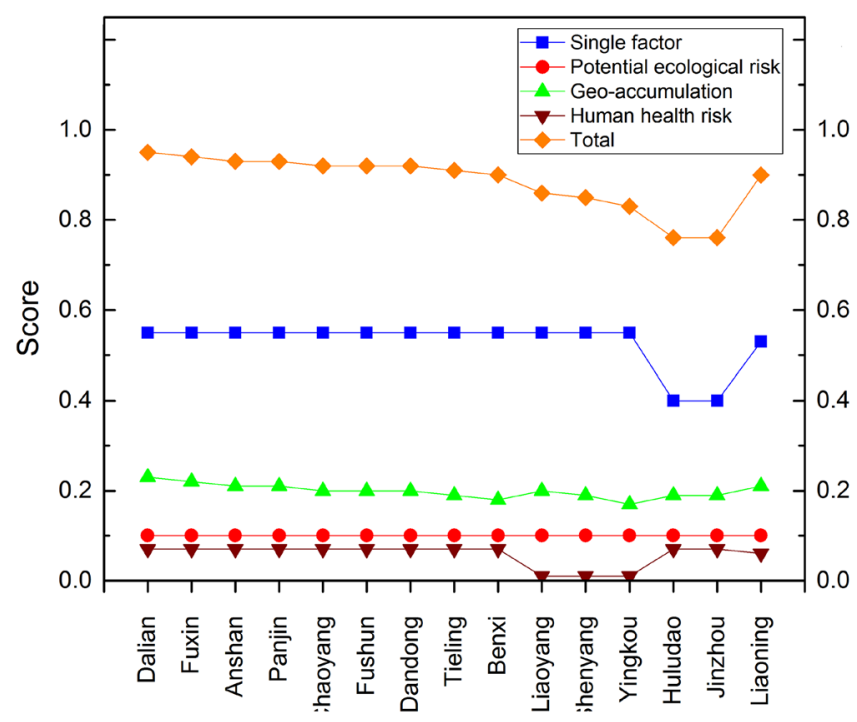

Figure 5. Comprehensive assessment of heavy metal pollution level.

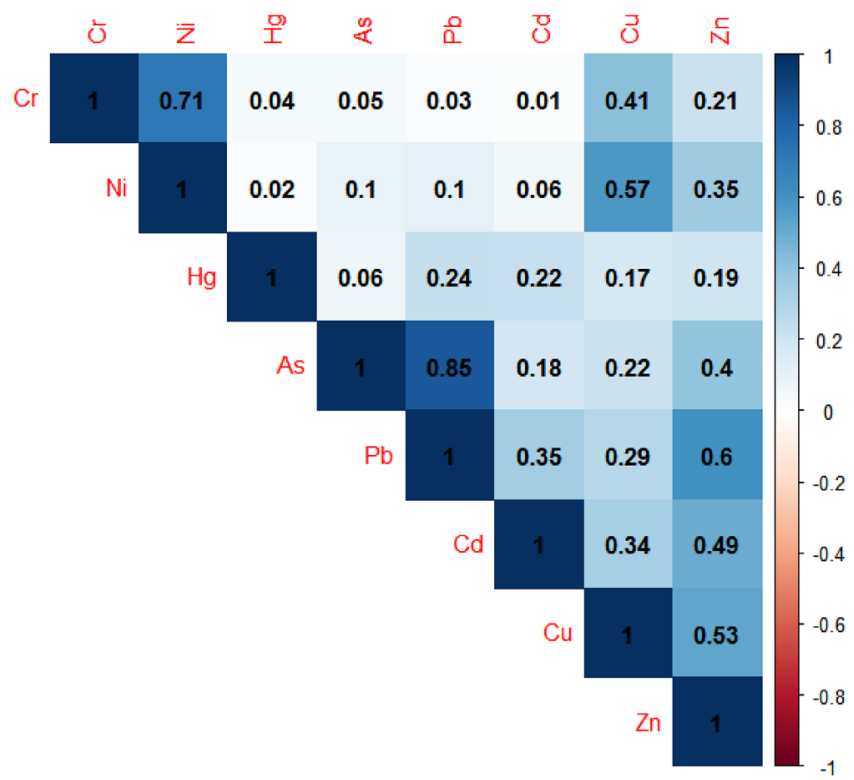

Figure 6. Correlation analysis of 8 heavy metals.

homologous. Other heavy metals showed moderate correlation, like As and $\mathrm{Zn}(\mathrm{r}=0.396, P<0.01), \mathrm{Cr}$ and $\mathrm{Cu}$ $(\mathrm{r}=0.411, P<0.01)$ indicating that their sources were complex.

Principal component analysis (PCA) of 8 heavy metals extracted three principal components. The cumulative variance contribution rate was $74.49 \%$, which reflected the most of information about the sources of heavy metals in soil ${ }^{44}$. In principal component 1 , the factor load values of $\mathrm{Cu}(0.734), \mathrm{Pb}(0.749)$, As (0.628) and $\mathrm{Zn}(0.817)$ were large (Table 3 ). The pollution center values mostly appeared near non-ferrous metal smelts, which may be related to the industrial three wastes. In principal component $2, \mathrm{Cr}(0.732), \mathrm{Cu}(0.342)$ and $\mathrm{Ni}(0.708)$ were the main factors. According to the analysis of pollution characteristics, the areas with high pollution degree of $\mathrm{Cr}$, $\mathrm{Cu}$ and $\mathrm{Ni}$ were mostly concentrated near metal products processing plants. This showed that heavy metals were discharged more in the process of metal products processing. In principal component 3 , the factor load values of $\mathrm{Cd}(0.510)$ and $\mathrm{Hg}(0.638)$ were larger, and the areas with serious Cd pollution were mainly sewage irrigation areas. It reflected that sewage irrigation pollution was defined as the main pollution source.

Spatial analysis of pollution level. The spatial distribution map of the comprehensive evaluation score can understand the soil quality of the study area more directly (Fig. 7). The comprehensive results of pollution level also showed a certain feature. Soil pollution, centered on industrial and mining enterprises, spreads around 


\begin{tabular}{|c|c|c|c|}
\hline \multirow[b]{2}{*}{ Heavy metals } & \multicolumn{3}{|c|}{ Component } \\
\hline & 1 & 2 & 3 \\
\hline As & 0.628 & -0.483 & -0.419 \\
\hline $\mathrm{Cd}$ & 0.542 & -0.262 & 0.510 \\
\hline $\mathrm{Cr}$ & 0.456 & 0.732 & -0.137 \\
\hline $\mathrm{Hg}$ & 0.312 & -0.171 & 0.638 \\
\hline $\mathrm{Pb}$ & 0.749 & -0.534 & -0.273 \\
\hline $\mathrm{Cu}$ & 0.734 & 0.342 & 0.153 \\
\hline $\mathrm{Zn}$ & \begin{tabular}{|l|}
0.817 \\
\end{tabular} & -0.116 & 0.101 \\
\hline $\mathrm{Ni}$ & 0.578 & \begin{tabular}{|l|}
0.708 \\
\end{tabular} & -0.133 \\
\hline
\end{tabular}

Table 3. Principal component analysis of heavy metals in soil.

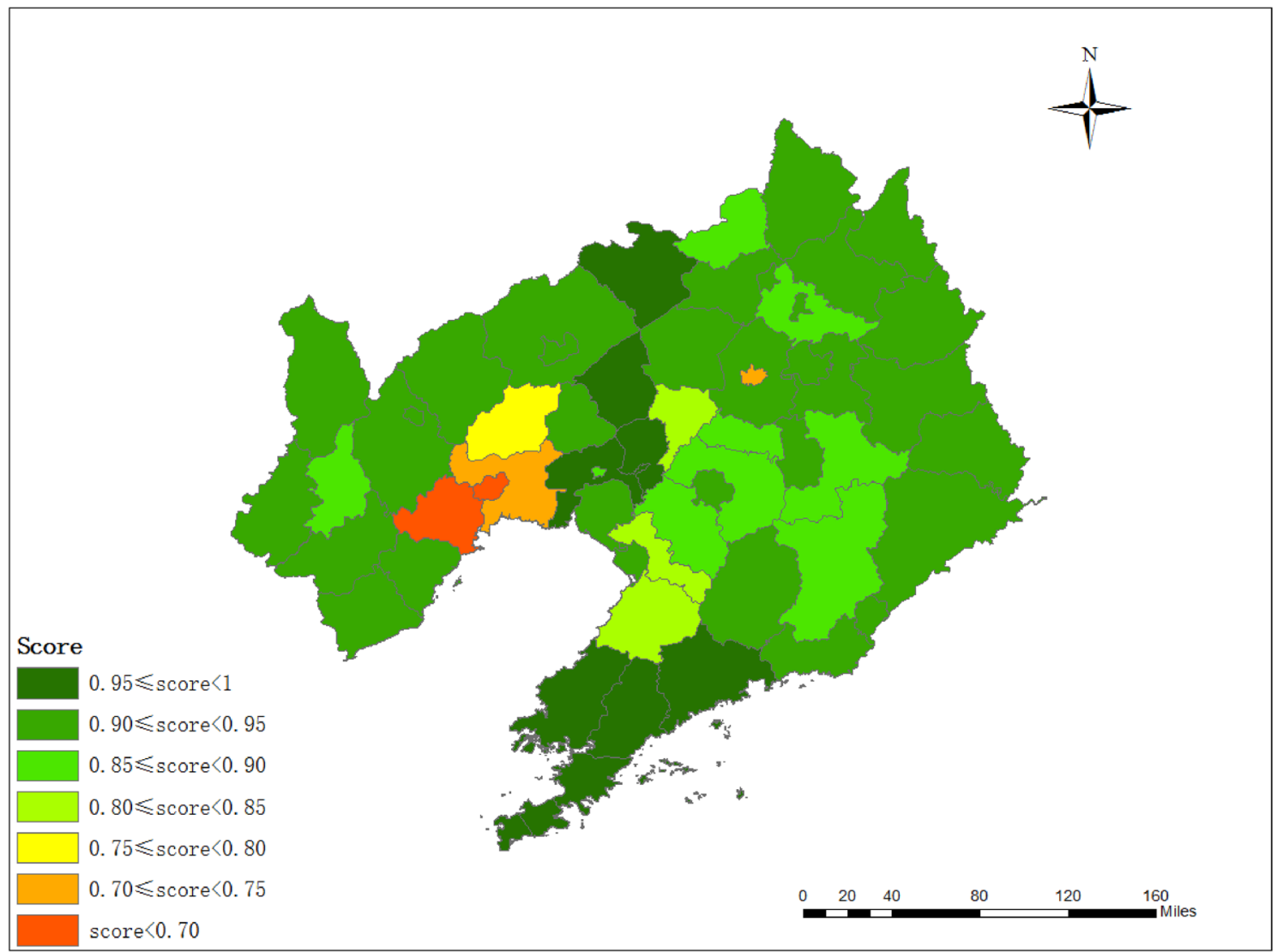

Figure 7. The spatial distribution map of the comprehensive assessment result. The map was created in ArcMap 10.2: https:// www. esri. Com (Esri, California, USA).

and showed a downward trend. The pollution in the sewage irrigation area was distributed in bands. The spatial characteristics were caused by many factors such as soil parent material, agricultural activities and industrial activities ${ }^{45,46}$. Different cities have different degrees of heavy metal accumulation due to their own characteristics. Specific policies should be designed for different cities ${ }^{47}$. Such as Huludao, Jinzhou, Dandong and Benxi, their heavy metals pollution may be dominated by non-ferrous metal mining activities, and the government should resolutely close mines that do not meet environmental requirements ${ }^{48}$. In addition, enterprises should upgrade their production processes and strengthen existing environmental protection measures to reduce the total amount of heavy metal emissions. It is an effective measure to protect soil environmental quality to strengthen the standardized treatment of pollutants discharged by enterprises in cities with heavy metal industry ${ }^{49}$. The quantity and quality of fertilizer should be strictly controlled in cities where heavy metal accumulation is mainly agricultural. The accumulation of heavy metals in topsoil can cause vertical migration and aggravate groundwater pollution ${ }^{50}$. The accumulation of heavy metals in soil is a dynamic process which is affected by many factors ${ }^{51}$. A monitoring network should be established for long-term monitoring of dynamic changes in soil quality, which can provide accurate and up-to-date information for decision-maker ${ }^{52}$. It ensures that the carcinogenic and noncarcinogenic risks of heavy metal to the human body are controllable. 


\section{Conclusions}

The soil contamination assessment and investigation of soil quality have to be still regulated worldwide. This study has reviewed and presented a set of maps with comprehensive assessment score in Liaoning province. The current pollution level of heavy metals in soil and spatial features across Liaoning were demonstrated effectively by these maps. The concentrations of heavy metals and comprehensive assessment score in soil varied significantly. The result shows that Liaoning province assessment scores were 0.8998 (T), 0.9720 (SF), 1.0000 (PER), 0.8268 (GEO), and 0.5849 (HHR). The weight coefficients of 4 evaluation methods were 0.55 (SF), 0.10 (PER), 0.25 (GEO), and 0.10 (HHR). 8 heavy metals weight coefficient (As, Cd, Cr, Hg, Pb, Cu, Zn, Ni) accounted for $0.10,0.31,0.02,0.41,0.05,0.05,0.01,0.05$, respectively. Heavy metal contents in most cities were greater than corresponding average background values. Most of the contaminated regions located in central and western Liaoning. Cd was found to be most polluted in soil in Liaoning. It needs to be vigilant about potential threat from $\mathrm{Cd}$ which was defined as mainly concerned pollution elements. Overall, the overall quality of farmland soil was still at low risk level except several key areas. These results can enhance our knowledge of heavy metal pollution status, potential health risks, and potential controlling factors for heavy metal accumulation in different regions across Liaoning. It also provides more comprehensive and up-to-date information for contributing to better soil management, soil remediation, and soil contamination control.

\section{Data availability}

The datasets used and/or analyzed during the current study are available from the corresponding author on reasonable request.

Received: 11 September 2021; Accepted: 22 February 2022

Published online: 03 March 2022

\section{References}

1. Ma, C. Y., Cai, D. J. \& Yan, H. Soil Cd pollution and research progress of treatment techniques. Henan Chem. Ind. 30(16), 17-22 (2013).

2. Min, Y. T., Zhang, H. M., Shen, F. X. \& Li, Y. Discussion on the protection and utilization of topsoil resources. Green Technol. 20, $18-20$ (2018).

3. Zhou, R. et al. Remediation of $\mathrm{Cu}, \mathrm{Pb}, \mathrm{Zn}$ and $\mathrm{Cd}$-contaminated agricultural soil using a combined red mud and compost amendment. Int. Biodeterior. Biodegrad. 118, 73-81. https://doi.org/10.1016/j.ibiod.2017.01.023 (2017).

4. MEEC (Ministry of Ecology and Environment of China). National Soil Pollution Survey Bulletin (2019). http://www.zhb.gov.cn/ $\mathrm{gkml} / \mathrm{hbb} / \mathrm{qt} / 201404 / \mathrm{t} 20140417 \_270670 . \mathrm{html}$.

5. Bermudez, G. M. A., Jasan, R. \& Pla, R. Heavy metals and trace elements in atmospheric composition out: their relationship with topsoil and wheat element. J. Hazard Mater. 213-214, 447-456 (2012).

6. Cheng, K., Tian, H. Z. \& Zhao, D. Atmospheric emission inventory of cadmium form anthropogenic sources. Int. J. Environ. Sci. Te. 11, 605-616 (2014).

7. Rai, P. K., Lee, S. S., Zhang, M., Tsang, Y. F. \& Kim, K. H. Heavy metals in food crops: health risks, fate, mechanisms, and management. Environ. Int. 125, 365-385 (2019).

8. Chen, Y. Y. et al. Heavy metal pollution assessment of farmland soil in China based on bibliometrics. Chin. J. Soil Sci. 47, 219-225 (2016).

9. Khan, M. et al. Global soil pollution by toxic elements: Current status and future perspectives on the risk assessment and remediation strategies-A review. J. Hazard Mater. 417, 126039 (2021).

10. Li, H. et al. Effects of red mud based passivator on the transformation of Cd fraction in acidic Cd-polluted paddy soil and Cd absorption in rice. Sci. Total Environ. 640, 736-745 (2018).

11. Hou, D. et al. Metal contamination and bioremediation of agricultural soils for food safety and sustainability. Nat. Rev. Earth Environ. 1, 366-381 (2020).

12. Rajendran, S. et al. A critical review on various remediation approaches for heavy metal contaminants removal from contaminated soils. Chemosphere 287, 132369 (2021).

13. Ahmed, S.F., Mofijur, M., Nuzhat, S., Chowdhury, A.T., Rafa, N., Uddin, M.A., Inayat, A., Mahlia, T.M.I., Ong, H.C., Chia, W.Y. \& Show, P.L. Recent developments in physical, biological, chemical, and hybrid treatment techniques for removing emerging contaminants from waste water. J. Hazard Mater. p 125912 (2021).

14. Adam, A. M. A. et al. Detection of environmental pollutants heavy metal ions based on the complexation with fluorescent dyes: Reaction of 2-(2'-hydroxyphenyl)-5-amino-benzotriazole with the $\mathrm{Sn}^{2+}, \mathrm{Hg}^{2+}$, and $\mathrm{Pb}^{2+}$ ions. Inorg. Chem. Commun. 124, 108408 (2021).

15. Nayak, M. C., Isloor, A. M., Lakshmi, B., Marwani, H. M. \& Khan, I. Polyphenylsulfone/ multiwalled carbon nanotubes mixed ultra filtration membranes: Fabrication, characterization and removal of heavy metals $\mathrm{Pb}^{2+}, \mathrm{Hg}^{2+}$, and $\mathrm{Cd}^{2+}$ from aqueous solutions. Arab. J. Chem. 13(3), 4661-4672 (2020).

16. Kong, F. B. \& Liu, Y. Comparison of single factor index method and Nemerow index method in soil environmental quality evaluation. Gansu Sci. Technol. 30(03), 21-22 (2014).

17. Xie, W. et al. Application of multiple evaluation methods to soil environmental quality evaluation of main walnut producing areas in Tianjin. Geophys. Geochem. Explor. 45(01), 207-214 (2021).

18. Wang, L., Kwok, J. S., Tsang, D. C. \& Poon, C. S. Mixture design and treatment methods for recycling contaminated sediment. J. Hazard. Mater. 283, 623-632 (2015).

19. Luo, F., Wu, G. R., Wang, C. \& Zhang, L. Application of Nemerow pollution index method and single factor evaluation method in water quality evaluation. Envrion. Sustain Dev. 41(05), 87-89 (2016).

20. Hou, D. Divergence in stakeholder perception of sustainable remediation. Sustain. Sci. 11, 215-230 (2016).

21. Ni, Z. Y., Xie, G. X. \& Zhang, M. K. Research progress of Cd contaminated farmland soil remediation technology. Anhui. Agronomy. Bull. 23(06), 115-120 (2017).

22. Zhao, Q. G. \& Luo, Y. M. The macro strategy of soil protection in China (In Chinese). Bull. Chin. Acad. Sci. 30(4), 452-458 (2015).

23. Su, Q. L. et al. Comparative study on several regional soil heavy metal pollution assessment methods. J. Environ. Sci. 36(04), 1309-1316 (2016).

24. Yoo, J. C. et al. A combination of ferric nitrate/EDDS-enhanced washing and sludge-derived biochar stabilization of metalcontaminated soils. Sci. Total Environ. 616, 572-582 (2018).

25. Zhou, C. Research progress in in situ remediation of Cd contaminated soil. Design Res. Non-ferrous Metall. 39(05), 20-28 (2018). 
26. Shi, T. R. et al. Mass balance-based inventory of heavy metals inputs to and outputs from agricultural soils in Zhejiang Province, China. Sci. Total Environ. 649, 1269-1280 (2019).

27. MEEC (Ministry of Ecology and Environment of China). The Technical Specification for Soil Environmental Monitoring (HJ/T 166-2004). Chinese Standard: Beijing, China, 4-17. http://kjs.mee.gov.cn/hjbhbz/bzwb/jcffbz/200412/t20041209_63367.shtml (2004).

28. $\mathrm{Xu}$, Z. et al. Comprehensive evaluation of soil quality in a desert steppe influenced by industrial activities in northern China. Sci. Rep. 11, 17493. https://doi.org/10.1038/s41598-021-96948-7 (2021).

29. Bartkowiak, A., Lemanowicz, J. \& Lamparski, R. Assessment of selected heavy metals and enzyme activity in soils within the zone of influence of various tree species. Sci. Rep. 10, 14077. https://doi.org/10.1038/s41598-020-69545-3 (2020).

30. MEEC (Ministry of Ecology and Environment of China), State Administration for Market Regulation. Soil environmental quality Risk control standard for soil contamination of agricultural land: GB 15618-2018. Beijing: China Environmental Press (2018).

31. Müller, G. Index of geoaccumulation in sediments of the Rhine River. Geo J. 2, 108-118 (1969).

32. Ji, Y. Q. et al. Using geoaccumulation index to study source profiles of soil dust in China. J. Environ. Sci. 20, 571-578 (2008).

33. Hakanson, L. An ecological risk index for aquatic pollution control. A sedimentological approach. Water. Res. 14(8), 975-1001 (1980).

34. US EPA. Risk assessment guidance for superfund. In: Human Health Evaluation Manual (Part A), vol. 1. Environmental Protection Agency, Washington, DC 35-52 (1989).

35. US EPA. CASRN 7440-50-8 Copper. Environmental Protection Agency. Integrated Risk Information System, Washington (1991).

36. US EPA. Baseline Human Health Risk Assessment. Vasquez Boulevard and I-70 Superfund Site Denver, Denver (2001).

37. Zhao, H. D., Du, L. Y., Wu, Y., Wu, X. N. \& Han, W. Numerical assessment of the passivator effectiveness for Cd-contaminated soil remediation. Sci. Total Environ. https://doi.org/10.1016/j.scitotenv.2021.146485 (2021).

38. Zhang, X. X., Zha, T. G., Guo, X. P., Meng, G. X. \& Zhou, J. X. Spatial distribution of metal pollution of soils of Chinese provincial capital cities. Sci. Total Environ. 643, 1502-1513 (2015).

39. Yuan, X. H., Xue, N. D. \& Han, Z. G. A meta-analysis of heavy metals pollution in farmland and urban soils in China over the past 20 years. J. Environ. Sci. 101, 217-226 (2021).

40. Guo, G. H., Wu, F. C., Xie, F. C. \& Zhang, R. Q. Spatial distribution and pollution assessment of heavy metals in urban soils from southwest China. J. Environ. Sci. 24(3), 410-418 (2012).

41. Hu, B. F. et al. Assessment of heavy metal pollution and health risks in the soil-plant-human system in the Yangtze River delta, China. Int. J. Environ. Res. Public Health. 14(9), 1042 (2017)

42. Hu, B. F., Wang, J. Y., Jin, B., Li, Y. \& Shi, Z. Assessment of the potential health risks of heavy metals in soils in a coastal industrial region of the Yangtze River Delta. Environ. Sci. Pollut. Res. 24(24), 19816-19826 (2017).

43. Huang, T., Yue, X. J., Ge, X. Z. \& Wang, X. D. Evaluation of soil quality on gully region of loess plateau based on principal component analysis. Agri. Res. Arid Areas. 28(03), 141-147. https://doi.org/10.1016/S1002-0160(10)60014-8 (2010).

44. Jia, X. L. et al. A methodological framework for identifying potential sources of soil heavy metal pollution based on machine learning: a case study in the Yangtze Delta China. Environ. Pollut. 250, 601-609. https://doi.org/10.1016/j.envpol.2019.04.047 (2019).

45. Khalid, S. et al. A comparison of technologies for remediation of heavy metal contaminated soils. J. Geochem. Explor. 182, 247-268 (2017).

46. Beiyuan, J. et al. Integrating EDDS-enhanced washing with low-cost stabilization of metal-contaminated soil from an e-waste recycling site. Chemosphere 159, 426-432 (2016).

47. Beiyuan, J. et al. Fate of arsenic before and after chemical-enhanced washing of an arsenic-containing soil in Hong Kong. Sci. Total Environ. 599, 679-688 (2017).

48. Karimi, B. et al. Biogeography of soil bacteria and archaea across France. Sci. Adv. 4(7), eaat1808 (2018).

49. Cheng, W. et al. Geographic distribution of heavy metals and identification of their sources in soils near large, open-pit coal mines using positive matrix factorization. J. Hazard. Mater. 387, 121666. https://doi.org/10.1016/j.jhazmat.2019.121666 (2020).

50. Hu, B.F., Shao, S., Fu, T.T., Fu, Z.Y., Zhou, Y., Li, Y., Qi, L., Chen, S.C. \& Shi, Z. Composite assessment of human health risk from potentially toxic elementsthrough multiple exposure routes: a case study in farmland in an importantindustrial city in East China. J. Geochem. Explor. 106443 (2020).

51. Wang, G. et al. Riskassessment of metals in urban soils from a typical industrial city, Suzhou, Eastern China. Int. J. Environ. Res. Public Health. 14, 1025 (2017).

52. Yuan, C. \& Lei, M. Assessment on remediation heavy metal contaminated soil for agricultural security utilization. Guangdong Chem. Ind. 44(7), 138-140 (2017).

\section{Author contributions}

H.Z: Conceptualization, Methodology, Software, Data curation, Writing- Original draft preparation, Visualization Writing and Editing. L.D: Reviewing-writing, Investigation, Methodology, Project fund. Y.W: Investigation. X.L: Supervision, Data curation. Y.Y: Investigation. X.W: Software, Data curation.

\section{Funding}

We gratefully acknowledge the National Key Research and Development Program of China (Grant No. 2018YFC1801200).

\section{Competing interests}

The authors declare no competing interests.

\section{Additional information}

Supplementary Information The online version contains supplementary material available at https://doi.org/ 10.1038/s41598-022-07602-9.

Correspondence and requests for materials should be addressed to L.D.

Reprints and permissions information is available at www.nature.com/reprints.

Publisher's note Springer Nature remains neutral with regard to jurisdictional claims in published maps and institutional affiliations. 
(c) (i) Open Access This article is licensed under a Creative Commons Attribution 4.0 International cc) License, which permits use, sharing, adaptation, distribution and reproduction in any medium or format, as long as you give appropriate credit to the original author(s) and the source, provide a link to the Creative Commons licence, and indicate if changes were made. The images or other third party material in this article are included in the article's Creative Commons licence, unless indicated otherwise in a credit line to the material. If material is not included in the article's Creative Commons licence and your intended use is not permitted by statutory regulation or exceeds the permitted use, you will need to obtain permission directly from the copyright holder. To view a copy of this licence, visit http://creativecommons.org/licenses/by/4.0/.

(C) The Author(s) 2022 